\title{
Urban heat islands in humid and arid climates: role of urban form and thermal properties in Colombo, Sri Lanka and Phoenix, USA
}

\author{
R. Emmanuel ${ }^{1,2, *}$, H. J. S. Fernando ${ }^{2}$ \\ ${ }^{1}$ Department of Architecture, University of Moratuwa, Moratuwa 10400, Sri Lanka \\ ${ }^{2}$ Environmental Fluid Dynamics Program, Department of Mechanical and Aerospace Engineering, Arizona State University, \\ Tempe, Arizona 85287-9809, USA
}

\begin{abstract}
Using a micro-scale urban simulation program, we examined the sensitivity of air temperature and mean radiant temperature (MRT) of built-up urban cores to urban-area geometry (the density of buildings), thermal properties of human-made surfaces (albedo) and green cover (street trees), in 2 warm-climate cities: Pettah, Colombo (Sri Lanka) and downtown Phoenix, Arizona (USA). Air temperature and MRT are indicative of human thermal comfort, and their rural/urban gradients signify the urban heat island (UHI) effect. Although high albedo values lead to low daytime temperatures in both cities, the best thermal comfort, quantified by both the air temperature and MRT, was found in high-density development. Thus, density enhancement is a viable UHI mitigation option in built-up areas of warm climate cities. Manipulation of thermal properties is an alternative strategy, but the practical utility of high albedo surfaces is questionable. Additionally, some UHI mitigation options are more likely to bring improvements in MRT than in air temperature. Urban designers should use mitigation options that are based on human comfort, which is determined by both MRT and air temperature, rather than simply attempting to control air temperature alone.
\end{abstract}

KEY WORDS: Climate-sensitive urban design $\cdot$ Tropical climate $\cdot$ Desert climate $\cdot$ ENVI-met

\section{INTRODUCTION}

One of the most important tasks of contemporary urban planning is the creation of sustainable environments. This includes the design of outdoor spaces and buildings that provide adequate 'comfort' to inhabitants while optimizing energy, space, material and natural resources as well as meeting the aesthetic, cultural, social, economic, ethical and religious norms of the communities involved (Kennedy 2007). At its heart, such design should ensure both the psychological and physiological well being of inhabitants, of which 'thermal comfort' is a key factor. In the ISO 7730 (1994) standards (ISO: International Organization for Standardization), thermal comfort is defined as: 'That condition of mind which expresses satisfaction with the thermal environment.' Qualitatively, this definition is one that can be easily agreed upon, but it is difficult to quantify, given that each person is the expert on his/her own thermal comfort. Thermal environments are considered together with other factors such as air and water quality, noise level and light in evaluating the 'environmental quality'.

The human body operates most efficiently at $37^{\circ} \mathrm{C} \pm$ $1^{\circ} \mathrm{C}$ (body temperature; NIOSH 1986). A simple change of $1^{\circ} \mathrm{C}$ outside this range can initiate symptoms of hypothermia or heat stress. For efficient thermoregulation, the human body must operate at core temperatures of between 35 and $40^{\circ} \mathrm{C}$ (Keim et al. 2002). Once these limits are exceeded, serious health effects ensue. According to the NIOSH (1986), heat exposure can have both acute and chronic effects. Exposure to short-term heat events can cause fainting, heat stroke, heat rash, heat exhaustion, heat cramps, and death. 
Repeated exposure to high heat can result in chronic problems such as reduced heat tolerance and kidney stones (Keim et al. 2002). If employees perceive the environmental quality of the workplace as unsatisfactory, their working performance is known to adversely affect productivity and efficiency, due to slower work rates, increased numbers of errors and absenteeism. Effects of extremes of temperature translate to everyday life.

Usage levels of urban space are more likely to increase if the outdoor environment is thermally comfortable (Nikoloupoulou \& Steemers 2003, Hart et al. 2006). It is thought that thermal effects may be a limiting factor to urban growth. An example would be the 2 cities examined in the present study-Phoenix, Arizona and Colombo, Sri Lanka - where rising temperatures have been of major concern. The studies being conducted at Arizona State University (Jonathan Fink, presented at the Sedona Conference on Stable Boundary Layer, November 14 to 16, 2006) shows that thermal comfort-as opposed to scarce water resources - may be the limiting factor to growth of metropolitan Phoenix in the future. Colombo has already been subject to some outmigration toward cooler areas such as Kandy, due to the increasing trend of thermal discomfort.

The perception of thermal comfort is affected by air temperature, air movement (speed), humidity, clothing, activity level (i.e. the amount of physical work done), mean radiant temperature (MRT, a measure of thermal comfort) and many other factors. The MRT of an environment is defined as the uniform surface temperature of an imaginary black enclosure that would result in the same heat loss by radiation from the person as the actual non-uniform environment. Note that a person does not experience room temperature, rather, one experiences the heat lost from the body, the latter being determined by 4 key parameters: air temperature, humidity, MRT and air speed, all of which are, to an extent, controllable. There is a misconception that what matters most for thermal comfort is the air temperature, but the American Society of Heating, Refrigerating and Air-Conditioning Engineers (ASHRAE) has clearly identified MRT as equally important in determining levels of comfort. The two measures are somewhat interrelated; for example, a $1^{\circ} \mathrm{F}\left(0.55^{\circ} \mathrm{C}\right)$ increase in air temperature can be compensated by a decrease of $1.39^{\circ} \mathrm{F}\left(0.77^{\circ} \mathrm{C}\right)$ in MRT and vice versa (Koch 1962). Nevertheless, although the role that MRT plays in thermal comfort has been understood for several decades, it has not yet been integrated into building control systems (Gan 2001).

In the present study, we examined air temperature and MRT in urban cores, in particular how spatial planning (in terms of density of development) and material adaptations may improve the thermal comfort of Colombo and Phoenix, the climatic conditions of which are hot-humid and hot-arid, respectively. The major anthropogenically-induced urban temperature anomalies are manifested in the Urban Heat Island (UHI) effect, a microclimatic anomaly characterized by warmer nighttime temperatures in the core of a city compared to the surrounding rural environment.

Although the UHI occurs in cities worldwide, it poses a particular problem to the quality of life in warmer climates (Akbari 1995, Rosenfeld et al. 1998), since urban warming leads to unpleasant outdoor conditions and intensifies consumption of energy (at times of peak energy demand) for the cooling of buildings (Ahmed 2003, Spagnolo \& de Dear 2003, Johansson 2006, Rosenlund et al. 2006). Improved urban designs that maximise thermal comfort can raise the quality of life in general, as well as helping urban dwellers cope with episodes of hot weather (Kalkstein \& Valimont 1986) and allowing year-long outdoor activities (Correa 1989). Local thermal climate also impacts on mortality and morbidity, invasive species problems and epidemic outbreaks. In addition, thermally comfortable outdoor spaces have a positive influence on indoor climate (Rosenlund et al. 2006).

The results of the present study are intended to help planners select UHI mitigation options in warmclimate cities. An existing urban micrometeorological model (ENVI-met) was used for the calculations, which were evaluated against previously collected data.

\section{BACKGROUND}

\subsection{Causes of UHI effect}

Since the early work of Oke (1982), there is mounting evidence that urban geometry and thermal properties of surface material in urban areas (i.e. land use) are the major causes of UHIs (Oke 1987, Arnfield 1990). Urban geometry is measured in several different ways: (1) the building height:street width $(\mathrm{H}: \mathrm{W})$ ratio, measuring the street canyon (a 3-dimensional space bounded by the planes of street buildings that abut it); (2) the sky view factor (SVF), which signifies the fraction of sky dome visible from a given outdoor point; and (3) a 'compactness index' (Unger et al. 2006), which is defined as the ratio of building surface area (excluding the plan area) to the surface area of a cube which has the same volume as the building. Todhunter (1990) argued that for micro-scale phenomena urban geometry is more important, but at the meso-scale both geometry and surface thermal characteristics play an equal role.

In addition to urban geometry and surface thermal properties, the following factors also contribute to 
urban microclimate modifications: (1) anthropogenic heat (heat waste from combustion and metabolism); (2) urban 'greenhouse' effect (increased incoming long-wave radiation from polluted urban atmosphere); (3) evapotranspiration loss (reduction of green areas in cities lead to more sensible than latent heat transfer); and (4) wind shelter, i.e. reduced ability of wind to carry heat either as sensible or latent turbulent heat flux (Oke 1988, 1991, Todhunter 1990, Saitoh \& Hoshi 1993). Oke (1988) argued that non-geometrical effects such as heat capacity and anthropogenic heat release may be linked to urban geometries, since high density buildings are, by definition, associated with extensive land use (more artificial surfaces) and intense human activity (thus, higher amounts of waste heat).

On the temporal scale, Tomita et al. (2006) showed that the effect of urban geometry (i.e. SVF) and thermal properties (such as thermal conductivity) affect the UHI at different times of the day; the effect of thermal properties is apparent in the early evening while urban geometry exerts its influence both during the daylight and evening hours. The link between urban geometry and daytime air temperature in warm climates is well documented. In the hot humid summer of Dhaka, Bangladesh, Ahmed (1994) found that maximum air temperature decreased with increased $\mathrm{H}: W$ ratio. Similarly, in the hot, dry climate of Fez, Morocco, Johansson (2006) found that a very deep street canyon had a considerably lower air temperature than a shallow street canyon. In hot, humid Colombo, Sri Lanka, Emmanuel \& Johansson (2006) found intra-urban differences in maximum daily temperatures of up to $7 \mathrm{~K}$ between sites of different urban geometries.

\subsection{UHI and human well-being}

The human dimension of UHI is increasingly being documented. Deosthali (1999), in their study in Pune, India, found increasing levels of human discomfort, expressed in terms of the temperature-humidity index (THI). Studies in Colombo, Sri Lanka (Emmanuel 2005, Johansson \& Emmanuel 2006) show the deteriorating outdoor conditions in terms of the relative strain index (Kyle 1992) and physiologically equivalent temperature, PET (Mayer \& Höppe 1987, also see Höppe 1999, Matzarakis et al. 1999). Here, the relative strain index is the ratio of the amount of sweat evaporation needed for comfort to the amount of evaporation possible given ambient atmospheric conditions, and PET is a thermal index derived from the human energy balance for the evaluation of the thermal component of different climates, defined as the air temperature at which, in a typical indoor setting (without wind and solar radia- tion), the heat budget of the human body is balanced with the same core and skin temperature as under the complex outdoor conditions to be assessed. Similar findings have been reported from Dhaka, Bangladesh (Ahmed, 2003); Cambridge, England (Nikolopoulou \& Steemers 2003) and Sydney, Australia (Spagnolo \& de Dear 2003).

Urban dwellers have also changed their everyday behaviour in recent times, especially in medium and high-income groups, spending more time indoors than outdoors (Ahmed 2003). In the face of increasing discomfort experienced when outdoors, one might expect more human activities to occur indoors, necessitating increased use of air-conditioning which, in turn, exacerbates outdoor temperatures as the excess heat is emitted to the urban air (de Schiller \& Evans 1998, Baker et al. 2002). Another consequence is the increased use of water due to urbanization (Guhartakurta et al. 2005). This is especially problematic in hot, dry areas where water resources are scarce. Furthermore, UHIs add to the urban mortality/morbidity concerns (Kalkstein \& Davis 1989, Greene \& Kalkstein 1996). While heat waves in general are major health hazards, urban areas exacerbate these problems, even in temperate cities, during hot summers.

\subsection{Outdoor thermal comfort}

Attempts toward quantifying urban thermal comfort are relatively new, with early efforts traced only to the 1970s; for a review, see Jendritzky \& Nübler (1981). Although these attempts have helped modify existing indoor climate models in the context of outdoor environments, some new indices specifically suited for outdoor applications have also been developed recently, the most prominent among them being the PET.

ASHRAE's Standard 55 (ASHRAE 1995) specifies human comfort in terms of 6 variables: air temperature, air velocity, relative humidity, MRT, clothing insulation and metabolic rate (i.e. human activity). In an indoor situation it may be reasonable to assume the air temperature to be equal to MRT, but this is an oversimplification in the context of urban thermal comfort quantification due to a number of reasons ranging from psychological to physiological factors (Höppe 2002). Outdoors, large differences exist between MRTs, particularly in areas with direct solar radiation; for example, adjacent areas exposed to direct sunlight and shade have different MRTs although the air temperature is essentially the same. Thus, MRT assumes greater importance in estimating outdoor thermal comfort.

The MRT is often calculated as the weighted average temperature of surrounding surfaces. It is more 
complicated to calculate the MRT in an outdoor urban environment than indoor due to factors such as the exposure to solar radiation, the varying shapes and positions of buildings and the presence of objects such as trees, etc. In the present paper, this task is made easy by the simulation software which is able to generate MRT values for each cell at different heights above ground.

\section{METHODOLOGY}

The aim of the present study was to simulate MRT and air temperatures arising from hypothetical or planned changes to urban form (density) and thermal properties of human-made surfaces within heavily built up street canyons in Pettah, Colombo $\left(6^{\circ} 54^{\prime} \mathrm{N}\right.$, $79^{\circ} 54^{\prime} \mathrm{E}, 7.3 \mathrm{~m}$ above sea level, a.s.l.) and the central business district of Phoenix $\left(33^{\circ} 27^{\prime} \mathrm{N}, 112^{\circ} 04^{\prime} \mathrm{W}\right.$, $338 \mathrm{~m}$ a.s.l.). The results were intended to help us ascertain appropriate UHI mitigation options in the context of warm climates.

Data from 2 reference weather stations were used to initiate the micro-scale numerical model ENVI-met, as discussed below. For Colombo, Sri Lanka, the initial data came from the Colombo International Airport, Katunayake $\left(7^{\circ} 10^{\prime} \mathrm{N}, 79^{\circ} 53^{\prime} \mathrm{E}, 8.5 \mathrm{~m}\right.$ a.s.l. $)$ while for Phoenix, data from the Gila Bend Army Base $\left(33^{\circ} 18^{\prime} \mathrm{N}, 112^{\circ} 36^{\prime} \mathrm{W}, 237 \mathrm{~m}\right.$ a.s.l.) was used. Model verification used a set of measured data from Colombo proper (Emmanuel \& Johansson 2006) and measured data from the Arizona Department of Environmental Quality (ADEQ) monitoring station (1.2 km WSW of the Phoenix study area; see Fig. 2) (www.azdeq.gov/ environ/air/monitoring/monitor.html).

In the field of UHI mitigation, numerical models have the obvious advantage over field measurements because of their controllability as well as time and resource frugality. The non-linearity of the UHI problem lends itself to numerical simulations and is therefore increasingly popular in urban climatology (Arnfield 2003).

Urban microclimate models vary widely with regard to their physical basis and spatial/temporal resolution. Ali-Toudert \& Mayer (2006) provide a detailed critique of contemporary models at the micro-scale with fine temporal resolutions. They inferred that ENVI-met (Bruse 1999) is perhaps the only micro-scale computational fluid dynamic model that is capable of analyzing the thermal comfort regime within the street canyon at fine resolutions (down to $0.5 \times 0.5 \mathrm{~m}$ ). We therefore selected ENVI-met as the numerical model to analyze the effect of UHI mitigation options in the present study (Bruse 2004; a freeware version is available from www.envi-met.com).
ENVI-met is a 3-dimensional non-hydrostatic model for the simulation of surface-plant-air interactions, especially within the urban canopy layer. It is designed for the micro-scale with a typical horizontal resolution from 0.5 to $10 \mathrm{~m}$ and a typical time frame of 24 to $48 \mathrm{~h}$ with a time step of $10 \mathrm{~s}$. This resolution allows the investigation of small-scale interactions between individual buildings, surfaces and plants (Bruse 2004).

Input meteorological data required to initiate ENVImet simulations are:

- Wind speed and direction at $10 \mathrm{~m}$ above ground

- Roughness length $\left(\mathrm{Z}_{\mathrm{o}}\right)$

- Initial temperature of the atmosphere

- Specific humidity at $2500 \mathrm{~m}$

- Relative humidity at $2 \mathrm{~m}$

The model calculation includes:

- Short- and long-wave radiation fluxes with respect to shading, reflection and re-radiation from building systems and the vegetation

- Transpiration, evaporation and sensible heat flux from the vegetation into the air, including full simulation of all plant physical parameters (e.g. photosynthesis rate)

- Surface and wall temperatures for each grid point and wall

- Water and heat exchange inside the soil system

- Calculation of bio-meteorological parameters such as MRT or predicted mean vote (PMV) (Fanger 1970)

- Dispersion of inert gases and particles including sedimentation of particles on leaves and surfaces.

A shortcoming of ENVI-met is that buildings, which are modeled as blocks where width and length are multiples of grid cells, have no thermal mass and have constant indoor temperature. Moreover, albedo and thermal transmission (U-value) for walls and roofs are the same for all buildings. Details of the calculation procedures are described in Bruse (1999, 2004) and Ali-Toudert \& Mayer (2006). Topographical and urban morphological information for our case studies were obtained from the Department of Surveys, Sri Lanka and 'Google Earth' (http:// earth.google.com/). Also, building data for an area $16.7 \mathrm{~km}^{2}$ for Phoenix is available from Burian et al. (2002).

The building morphology for the Pettah, Colombo and Phoenix downtown areas are shown in Figs. $1 \& 2$ respectively. The 2 areas shown are approximately $0.2 \times 0.15$ and $0.15 \times 0.15 \mathrm{~km}$, respectively. Both sites are heavily built up and the Colombo site is totally devoid of greenery (minimal green cover is present in the Phoenix case).

In order to test the efficacy of commonly suggested UHI mitigation options, the present study simulated the following scenarios for each site: 
a

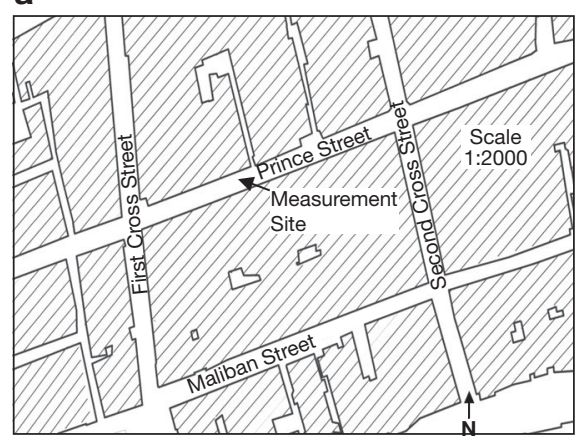

Fig. 1. Case study - Pettah, Colombo. (a) Building footprint and (b) ENVI-met representation. Grid cells in ENVI-met panel are 5 $\times 5 \mathrm{~m}$; numbers in gridcells: building height $(\mathrm{m})$. Grey/black lines: change in building height between adjacent buildings; NS and EW: north-south and east-west running streets, respectively
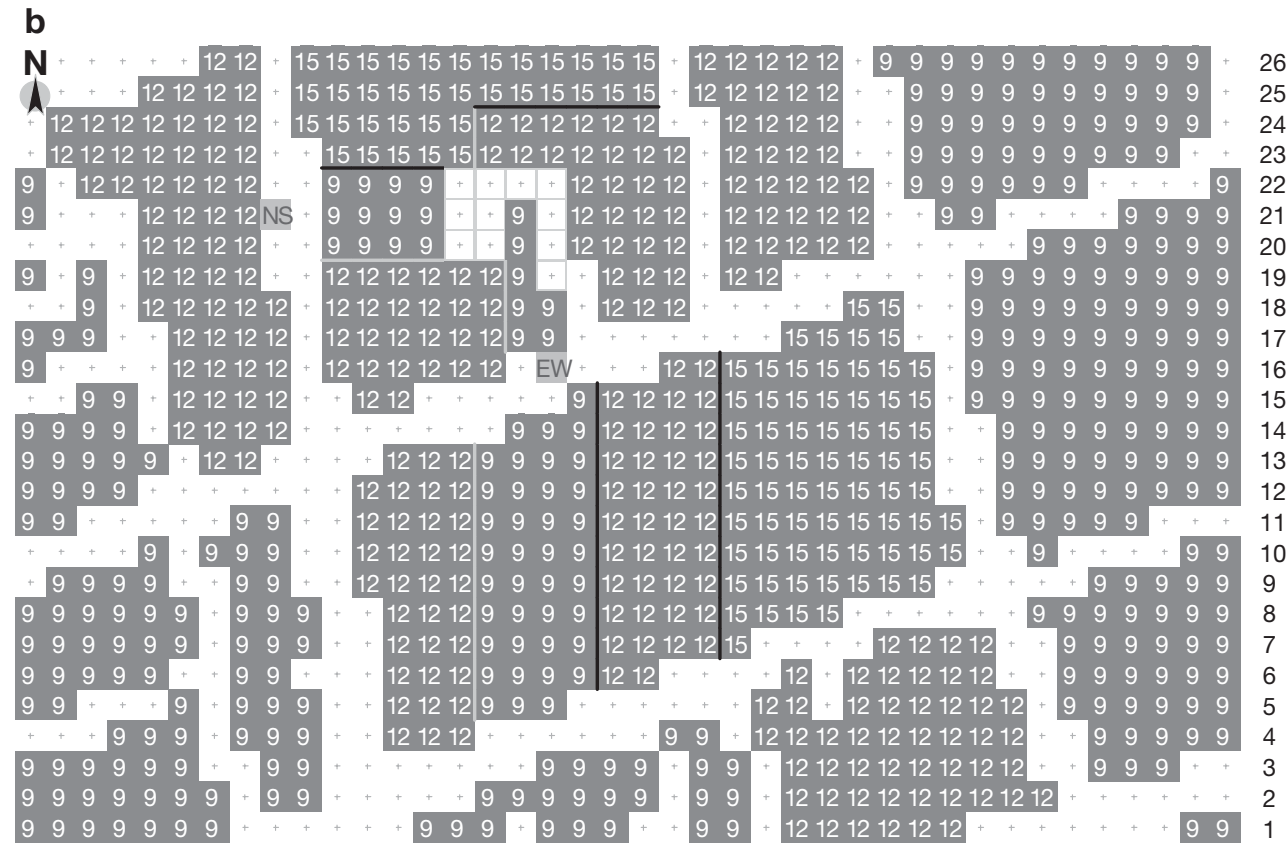

1234566789910111213141516171819202122232425262728293031323334353637383940
- 'Base'-existing situation

- 'High albedo' - all artificial surfaces to be painted in white

- 'High density' — all buildings in the model area to be as tall as the urban development regulations will permit

- 'Green'-introduction of a row of street trees in each street.

The parameters of each of these scenarios are shown in Table 1. The variables are defined as: $U_{\mathrm{w}}$ thermal transmittance (or U-value) of walls (assumed to be made of brick and rendered with mortar); $U_{\mathrm{r}}$ thermal transmittance of roofs (assumed to be made of reinforced cement concrete and rendered, both sides); and $\alpha_{\mathrm{w}}, \alpha_{\mathrm{r}}$ and $\alpha_{\mathrm{s}}$ albedo (ratio of reflected to incident radiation) of walls, roofs and streets, respectively. The high albedo scenario is assumed to be 'all white' (i.e. walls, roofs and street surfaces are white/light colored).

Table 1. Parameters of UHI mitigation scenarios. See 'Methodology' for outline descriptions of the different scenarios

\begin{tabular}{|c|c|c|c|}
\hline \multirow{2}{*}{ Scenario } & \multirow{2}{*}{ Urban geometry } & \multirow{2}{*}{$\begin{array}{l}\text { Parameters } \\
\text { Surface thermal properties }\end{array}$} & \multirow[b]{2}{*}{ Green cover } \\
\hline & & & \\
\hline \multicolumn{4}{|c|}{ Pettah, Colombo, Sri Lanka } \\
\hline Base & Uneven, to match existing geometry & $\begin{array}{l}U_{\mathrm{w}}=1.94 \mathrm{Wm}^{-2} \mathrm{~K} \\
U_{\mathrm{r}}=6.00 \mathrm{Wm}^{-2} \mathrm{~K} \\
\alpha_{\mathrm{w}}=\alpha_{\mathrm{r}}=\alpha_{\mathrm{s}}=0.60\end{array}$ & None \\
\hline Medium-density & All buildings $18 \mathrm{~m}$ (6 stories) high & Same as base scenario & None \\
\hline High-density & All buildings $24 \mathrm{~m}$ (8 stories) high & Same as base scenario & None \\
\hline Green & Same as base scenario & Same as base scenario & $\begin{array}{l}10 \mathrm{~m} \text { (canopy) street trees at } 20 \mathrm{~m} \text { intervals } \\
\text { (Stem height }=10 \mathrm{~m})\end{array}$ \\
\hline High albedo & Same as base scenario & $\begin{array}{c}U_{\mathrm{w}}=0.57 \mathrm{Wm}^{-2} \mathrm{~K} \\
U_{\mathrm{r}}=2.00 \mathrm{Wm}^{-2} \mathrm{~K} \\
\alpha_{\mathrm{w}}=\alpha_{\mathrm{r}}=\alpha_{\mathrm{s}}=0.90\end{array}$ & None \\
\hline \multicolumn{4}{|c|}{ Downtown Phoenix, AZ, USA } \\
\hline Base & Uneven, to match existing geometry & $\begin{array}{l}U_{\mathrm{w}}=1.94 \mathrm{Wm}^{-2} \mathrm{~K} \\
U_{\mathrm{r}}=6.00 \mathrm{~W} \mathrm{~m}^{-2} \mathrm{~K} \\
\alpha_{\mathrm{w}}=\alpha_{\mathrm{r}}=\alpha_{\mathrm{s}}=0.60\end{array}$ & Few trees to match existing green cover \\
\hline High-density & All buildings $36 \mathrm{~m}$ high & Same as base scenario & Same as base scenario \\
\hline Green & Same as base scenario & Same as base scenario & $\begin{array}{l}10 \mathrm{~m} \text { (canopy) street trees at } 20 \mathrm{~m} \text { intervals } \\
\text { (Stem height }=10 \mathrm{~m})\end{array}$ \\
\hline High albedo & Same as base scenario & $\begin{array}{l}U_{\mathrm{w}}=0.57 \mathrm{Wm}^{-2} \mathrm{~K} \\
U_{\mathrm{r}}=2.00 \mathrm{Wm}^{-2} \mathrm{~K} \\
\alpha_{\mathrm{w}}=\alpha_{\mathrm{r}}=\alpha_{\mathrm{s}}=0.90\end{array}$ & Same as base scenario \\
\hline
\end{tabular}


a

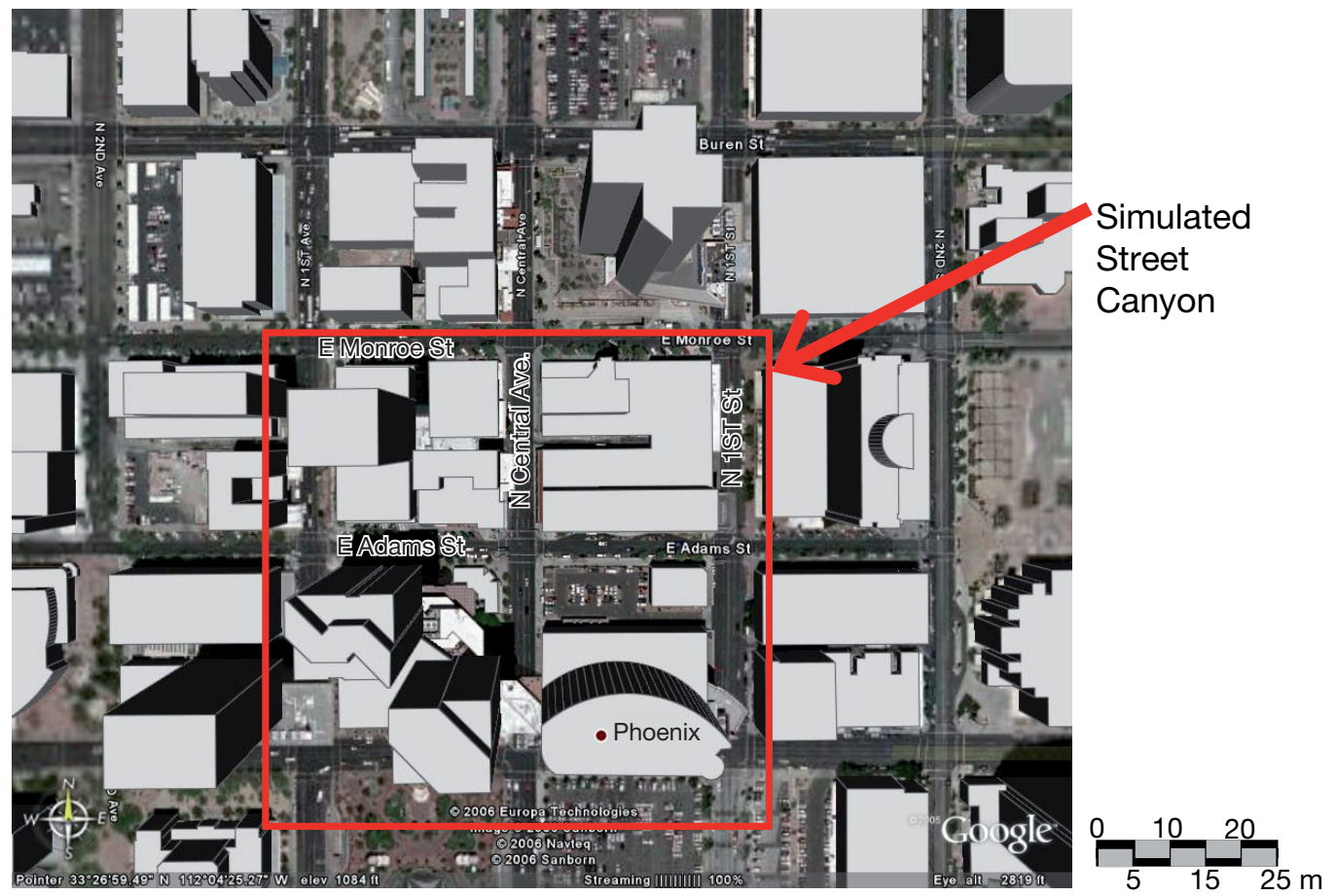

b

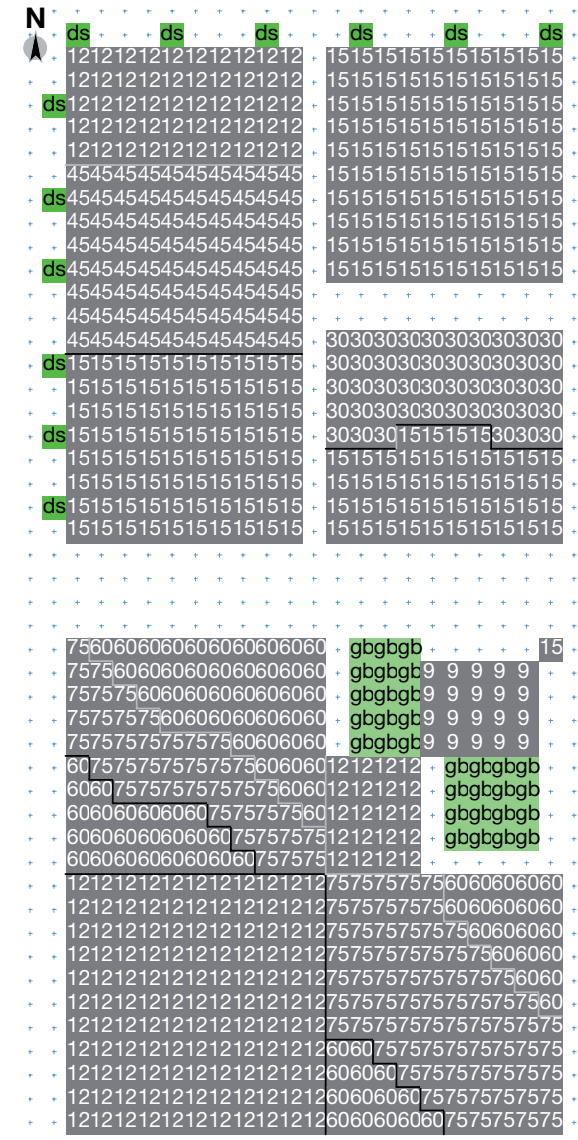

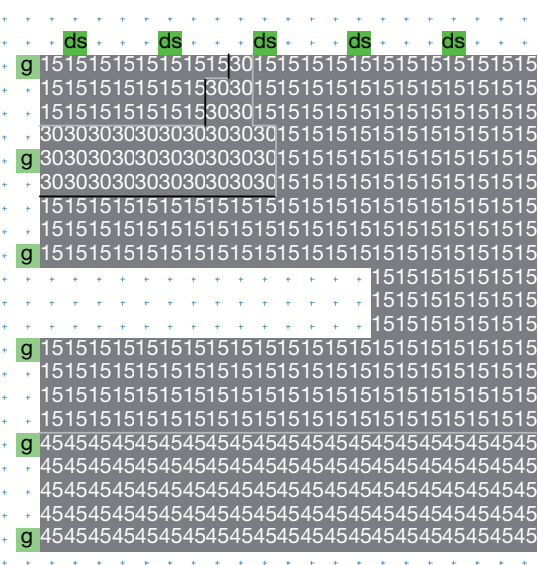

15

g

ds ds ds ds 29 $15151515151515+28$
$15151515151515+27$ $15151515151515+26$
$151515151515+25$ $15151515151515+25$ $15151515151515+24$

g 22

$+151515151515151515151515151515151515151515+21$ 151515151515151515151515151515151515151515
151515151515151515151515151515151515151515 g $151515151515151515151515151515151515151515+18$ $151515151515156060606060606015151515151515+17$ 151515151560606060606060606060601515151515 * 17 151515606060606060600606060606060151515 + 15 g 151515606060606060606060606060606060151515 + 14 $151560606060606060606060606060606060601515+13$ g $606060606060606060606060606060660606060606060+$ $606060606060606060606060606060606060606060+10$ $\begin{aligned} & 606060606060606060606060606060606060606060 \\ & 606060606060606060606060606060606060606060\end{aligned}+8$

6789101112131415161718192021222324252627282930313233343536373839404142434445464748495051525354

Fig. 2. Partial aerial view of downtown Phoenix. (a) Building footprint (from Google Earth ${ }^{\mathrm{TM}}$ ) and (b) ENVI-met representation. ds: tree; g: short grass; gb: long grass. See Fig. 1 legend for further information 


\section{RESULTS AND DISCUSSION}

\subsection{Numerical modeling: applicability}

Fig. 3 compares the ENVI-met simulations to actual measured data for Pettah, Colombo (Emmanuel \& Johansson 2006) and downtown Phoenix (ADEQ). For the Colombo case, the model tends to over-predict the air temperature at night (average absolute difference during $19: 00$ to $05: 00 \mathrm{~h}=0.27^{\circ} \mathrm{C}$; root mean square error $\operatorname{RMSE}=1.06^{\circ} \mathrm{C}$ ) and under-predicts during the day (average absolute difference during 07:00 to $17: 00 \mathrm{~h}=1.83^{\circ} \mathrm{C}$; RMSE $=2.73^{\circ} \mathrm{C}$ ). In the Phoenix case, the corresponding values are night $=1.99^{\circ} \mathrm{C}(\mathrm{RMSE}=$ $2.8^{\circ} \mathrm{C}$ ) and day $=2.00^{\circ} \mathrm{C}\left(\operatorname{RMSE}=2.61^{\circ} \mathrm{C}\right)$. Excessive nighttime temperature predictions of ENVI-met were also pointed out in previous works (e.g. Ali-Toudert \& Mayer 2006). One reason for the error is the absence of regional exchange processes. This could be significant in the Colombo case where the Indian Ocean lies only $0.5 \mathrm{~km}$ northwest of the modeled area shown on Fig. 1. Another reason could be the absence of thermal mass of buildings in the model. Furthermore, it is not possible to change the thermal properties of individual buildings (only an average value for the entire area

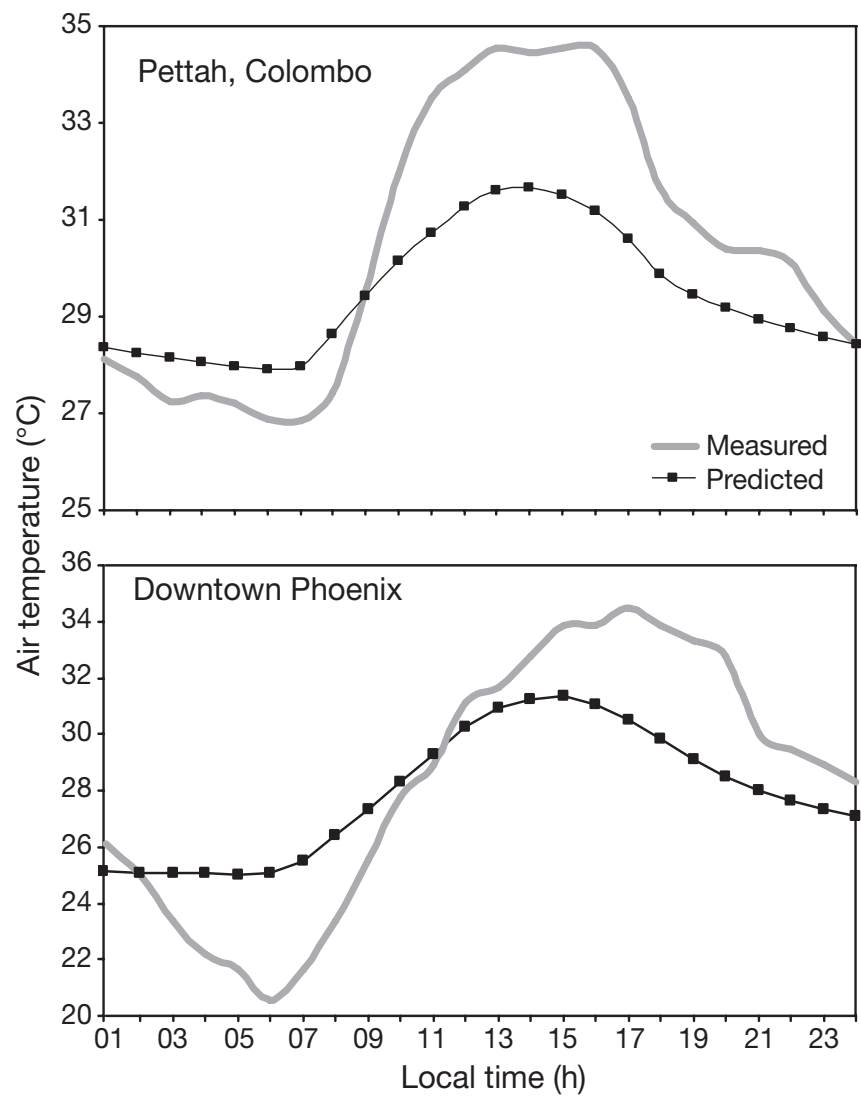

Fig. 3. Comparison of ENVI-met simulations with measured data for Pettah, Colombo, and downtown Phoenix could be given as a model input). Nevertheless, the RMSEs are not unacceptably large in comparison to the values usually recorded in the literature (e.g. Lee \& Fernando 2004), particularly considering the simplified nature of the model. It is to be noted that the error patterns are similar in both cases.

Since our purpose here is to compare the relative effects of individual UHI mitigation strategies for each city separately, it is felt that the ENVI-met results are useful even with the above-cited limitations.

\subsection{Comparison of mitigation strategies for Colombo}

Fig. 1 shows the existing building density in the heavily built-up commercial sector in the historic commercial area (Pettah) of Colombo, Sri Lanka. This area is typical of the high population density neighborhoods of Colombo. Colombo itself is typical of many warm, humid major cities in the developing world where high population density, scarce land availability, and the economic importance of capital cities have contributed to lop-sided urbanization centered on a few cities, resulting in significant UHI problems. The built fabric is characterized by wall-to-wall medium rise buildings (3 to 4 stories) on narrow streets. Surface cover is dominated by paved/asphalted streets with few trees.

Fig. 4 shows air temperature patterns at mid-canyon (1.2 $\mathrm{m}$ above street surface) for 2 streets in Colombo: (a) a north-south running street (1st Cross Street) and (b) an east-west running street (Prince Street), for a clear day in April 2003. The following general observations could be made:

- The largest daytime air temperature decrease occurs with higher albedo

- Density manipulation strategies lead to the second lowest daytime air temperatures

- No discernible improvement is seen with the green scenario.

\subsection{Comparison of mitigation strategies for downtown Phoenix}

As shown in Fig. 2, the land cover in downtown Phoenix is dominated by paved surfaces and tall ('sky scraper') buildings. As expected from a typical urban setting, the vegetation cover is sparse.

A comparison of air temperature patterns shown in Fig. 5 (which gives data for a north-south running street) reveals the following:

- None of the mitigation options produce significant air temperature differences during the day

- The 'high albedo' scenario produces somewhat lower daytime but higher nighttime air temperatures 


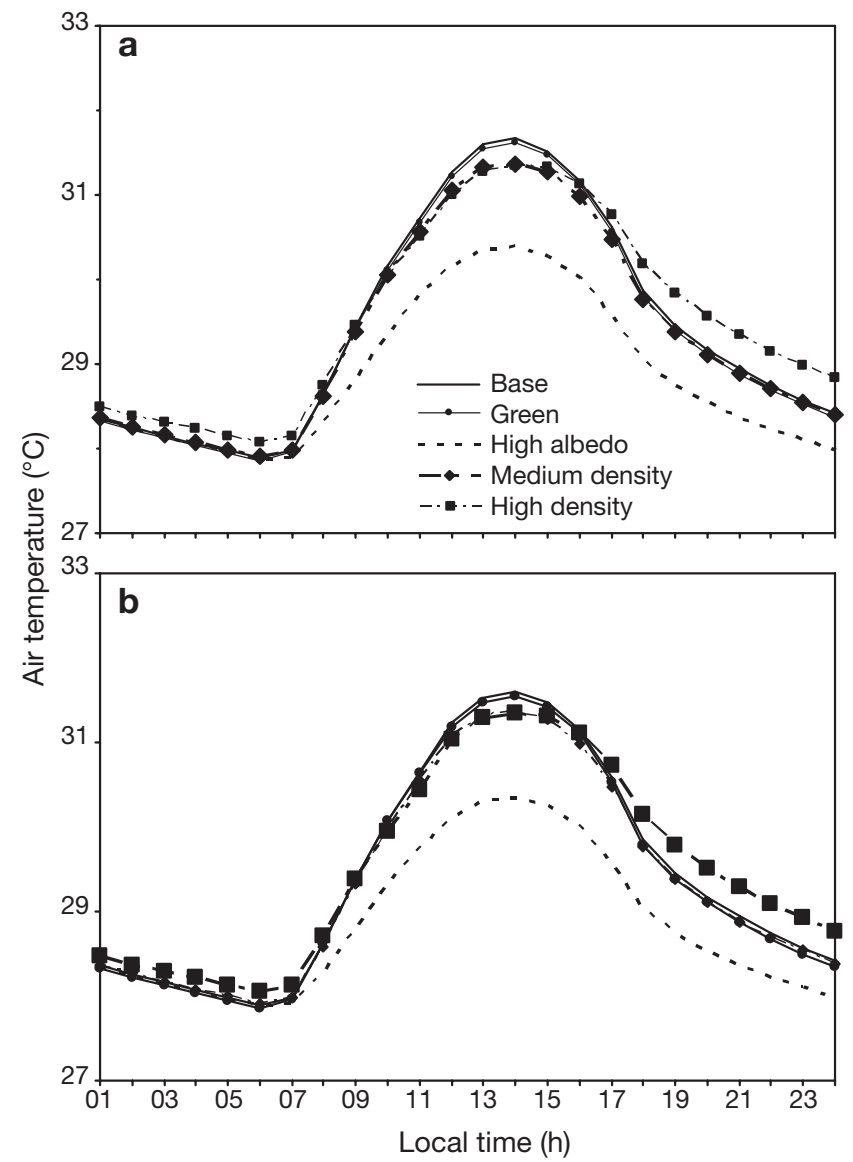

Fig. 4. Comparison of air temperatures for different UHI mitigation scenarios for (a) Prince Street and (b) 1st Cross Street, Colombo

- The lowest overall temperatures (day averaged) occur with high density.

While the differences in air temperature appear small, greater variation was seen in terms of MRT. Table 2 lists the range of MRT and air temperatures $1.2 \mathrm{~m}$ above the street, obtained from spatial distributions calculated by ENVI-met. An example of MRT patterns in daytime and nighttime for the Colombo case is shown in Fig. 6. According to Table 2, the lowest spread of MRT for Pettah, Colombo, occured in the 'high density' scenario, and the daytime differences are striking. The MRT variations in the 'high density' scenario were 36 to $42^{\circ} \mathrm{C}$ while the base scenario had a range of 45 to $66^{\circ} \mathrm{C}$ (north-south street). Variations in nighttime MRT were small. Similar patterns are seen in the Phoenix case as well (Table 2).

It appears that urban density (taller buildings) has a positive mitigating effect in the downtown core of both cities, although we found it had a greater effect on MRT than air temperatures. Since MRT is critical to outdoor thermal comfort, it is likely that high density development will lead to lower thermal dis-

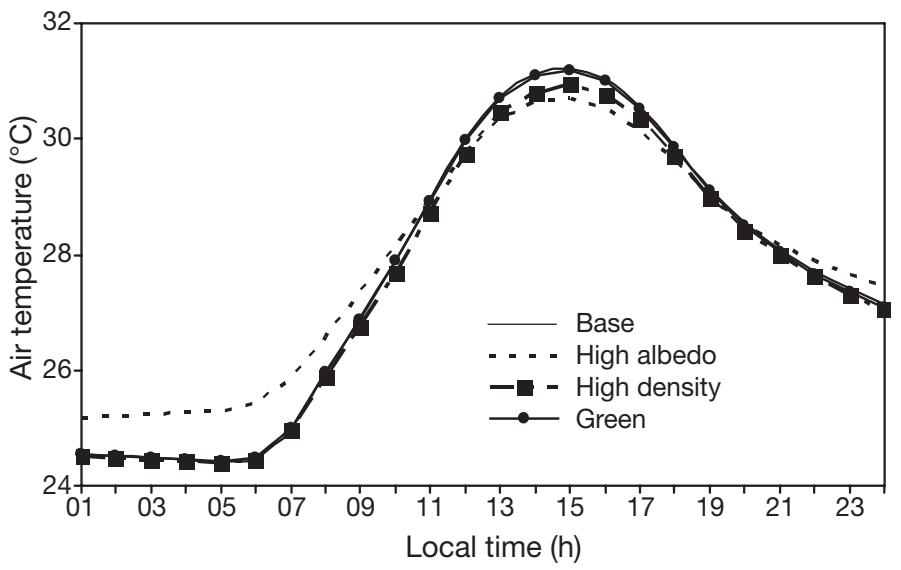

Fig. 5. Comparison of air temperatures for different UHI mitigation scenarios for North Central Avenue, Phoenix (see Fig. 2)

Table 2. Mean radiant temperature $\left(\mathrm{MRT},{ }^{\circ} \mathrm{C}\right)$ and air temperature $\left({ }^{\circ} \mathrm{C}\right)$ variations within street canyons during the day $(14: 00 \mathrm{~h})$ and night (21:00 h) in Pettah, Colombo and downtown Phoenix, Arizona. Data are for $1.2 \mathrm{~m}$ above street surface, except for Phoenix air temperature data (building rooftop). Scenarios-B: base; HA: high albedo; G: green; MD: medium density; HD: high density. (-) Simulation not run

\begin{tabular}{|c|c|c|c|c|c|}
\hline & B & HA & G & MD & HD \\
\hline \multicolumn{6}{|l|}{ MRT } \\
\hline \multicolumn{6}{|l|}{ Colombo } \\
\hline \multicolumn{6}{|c|}{ Prince St. (E-W) } \\
\hline Day & $48-66$ & $63-69$ & $46-62$ & $40-58$ & $36-42$ \\
\hline Night & $22-24$ & $22-23$ & $22-24$ & $22-23$ & $21-22$ \\
\hline \multicolumn{6}{|c|}{ 1st Cross St. (N-S) } \\
\hline Day & $45-66$ & $45-69$ & $46-62$ & $40-46$ & $36-42$ \\
\hline Night & $22-24$ & $21-23$ & $22-24$ & $22-23$ & $21-22$ \\
\hline \multicolumn{6}{|l|}{ Phoenix } \\
\hline \multicolumn{6}{|c|}{ Adams St. $(\mathrm{E}-\mathrm{W})$} \\
\hline Day & $51-83$ & $57-87$ & $51-83$ & - & $51-79$ \\
\hline Night & $29-33$ & $30-35$ & $29-33$ & - & $29-34$ \\
\hline \multicolumn{6}{|c|}{ N Central Avenue (N-S) } \\
\hline Day & $51-79$ & $57-92$ & $51-83$ & - & $51-83$ \\
\hline Night & $28-33$ & $30-34$ & $28-34$ & - & $29-34$ \\
\hline \multicolumn{6}{|c|}{ Air temperature } \\
\hline \multicolumn{6}{|c|}{ Colombo } \\
\hline \multicolumn{6}{|c|}{ Prince St. (E-W) } \\
\hline Day & $31.6-31.8$ & $30.4-30.5$ & $31.5-31.7$ & $31.3-31.4$ & $31.3-31.4$ \\
\hline Night & $28.8-29.0$ & $28.2-28.4$ & $28.5-29.0$ & $28.7-28.9$ & $29.2-29.3$ \\
\hline \multicolumn{6}{|c|}{ 1st Cross St. (N-S) } \\
\hline Day & $31.5-31.7$ & $30.3-30.4$ & $31.5-31.6$ & $31.3-31.5$ & $31.3-31.4$ \\
\hline Night & $28.8-29.0$ & $28.3-28.4$ & $28.5-28.9$ & $28.7-28.9$ & $29.2-29.3$ \\
\hline \multicolumn{6}{|l|}{ Phoenix } \\
\hline \multicolumn{6}{|c|}{ Adams St. (E-W) } \\
\hline Day & $31.0-31.2$ & $30.5-30.7$ & $31.0-31.2$ & - & $30.7-30.9$ \\
\hline Night & $28.0-28.2$ & $28.1-28.3$ & $27.9-28.1$ & - & $27.9-28.1$ \\
\hline \multicolumn{6}{|c|}{ N Central Avenue (N-S) } \\
\hline Day & $31.0-31.2$ & $30.5-30.7$ & $31.0-31.2$ & - & $30.7-30.9$ \\
\hline Night & $28.0-28.2$ & $28.1-28.3$ & $27.9-28.1$ & - & $27.9-28.1$ \\
\hline
\end{tabular}



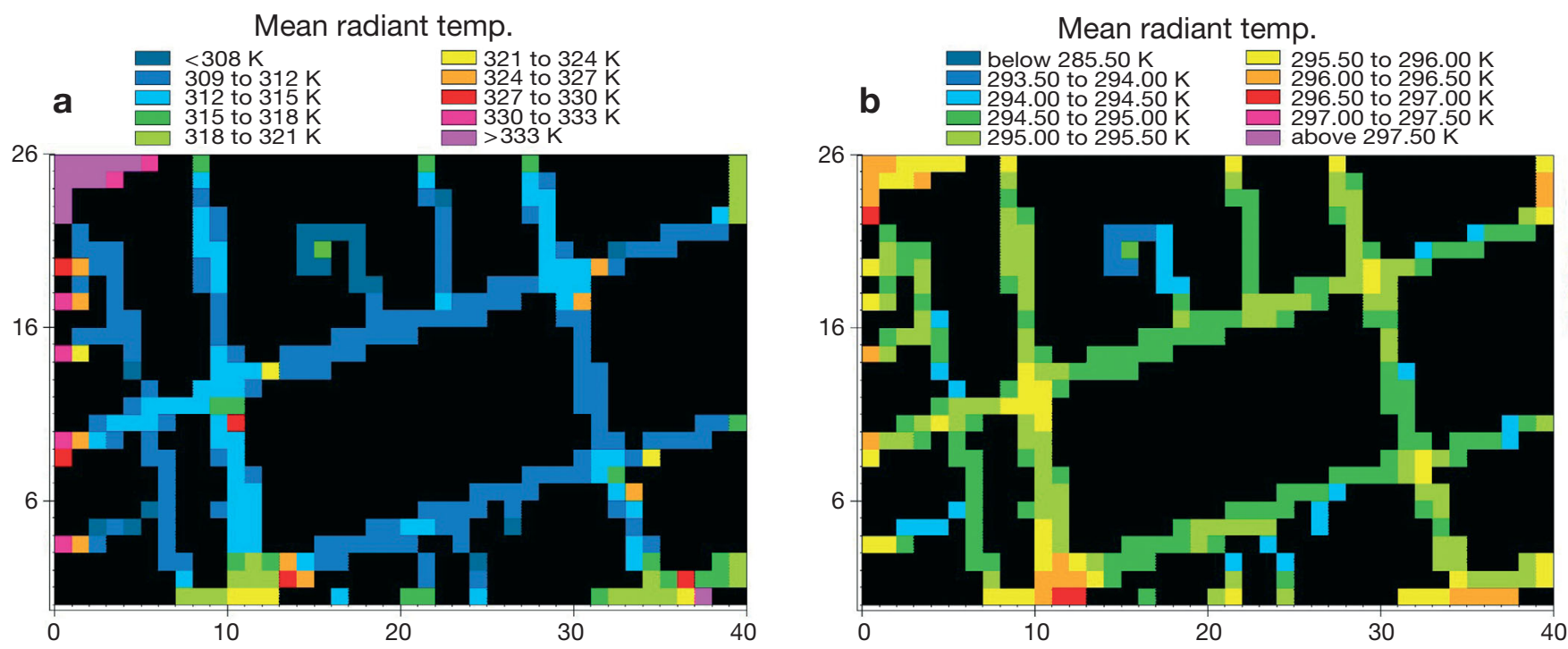

Fig. 6. MRT distribution in Pettah, Colombo: high density scenario during (a) daytime and (b) nighttime. Axis values: no. of pixels

comfort in the heavily built sections of these cities. This is especially true in the daytime hours where many human activities take place in urban street canyons.

The increase of albedo is a suitable mitigation option for daytime UHI, which is measured by the air temperature (Fig. 3). However, it must be kept in mind that the 'high albedo' scenario used in the present study assumes a light color for all urban surfaces (including streets). This is highly unlikely. Furthermore, the unexpected nighttime warming in the Phoenix case could be a problem, for which a likely explanation is the low building density even in the city core. Although there are tower-like buildings in the downtown core, the building density remains low (i.e. high SVF). It may also be a limitation of ENVI-met where buildings are not assigned thermal mass, and variation in thermal properties from one building to another is not possible.

The purpose of mitigating the UHI phenomenon is to enhance urban quality of life by promoting comfortable outdoor urban space. Since a significant portion of outdoor urban life happens during the daytime, urban density manipulation might prove a feasible UHI mitigation option. However, higher density development may have adverse effects on air movement (e.g. buffeting, turbulence) and pollution dispersal as well as on human health. These possible effects are not addressed in the present study.

Urban activities occur in clusters or patterns. An activity like shopping may involve transport to and from the shopping district, walking about in the shopping district, resting, eating, etc. A successful enhancement of urban quality of life will necessitate the development of strategies for UHI mitigation that address the entirety of such activity patterns. A combination of urban design options (high-density buildings or shading strategies to reduce outdoor MRT, plus enhancement of urban wind movement and pollution dispersal) will be needed to achieve this overarching goal.

\section{CONCLUSIONS}

One of the design implications of the present study is that density enhancement is a viable UHI mitigation option for cities in warm climates. In the high density settings of Colombo, it appears that thermal property manipulation is a suitable alternative, considering the limited wind movement and pollution dispersion limitations of density development. Here, high albedo leads to significantly lower daytime temperatures, which may reduce photochemical formation of certain pollutants, although this option may not help in terms of thermal comfort. In the case of Phoenix, the daytime reduction of temperature for high albedo and high density scenarios is much lower compared to the case of Colombo, but the improvements in MRT for thermal comfort are marginally better for the high density scenario.

A further implication is that some UHI mitigation options are more likely to show improvements in MRT than air temperatures (see, for example, Ali-Toudert et al. 2005). From an urban design point of view, mitigation options ought to focus on thermal comfort enhancement (including the MRT) rather than merely attempting to control air temperatures. 
Acknowledgements. The assistance of the following are gratefully acknowledged: Prof. Brian Harvey, College of Architecture and Environment Design, Arizona State University (discussions on thermal properties of building materials); Ms. Candice Hoff of the Aeronautics Divisions of the Sky Harbor International Airport, Phoenix (land cover information of the airport vicinity) and to the ADEQ (microclimate data from an ADEQ air quality monitoring station). The work was supported by the National Science Foundation (ATM) and in part by the Arizona State University (Office of the Vice President for Research and Economic Affairs).

\section{LITERATURE CITED}

Ahmed KS (1994) A comparative analysis of the outdoor thermal environment of the urban vernacular and the contemporary development: case studies in Dhaka. In: Etzion Y, Erell E, Meir IA, Pearlmutter D (eds) Architecture of the extremes. Proc 11th Passive and Low-Energy Architecture (PLEA) Int Conf Dead Sea, 3-8 July 1994. The Desert Architecture Unit, Ben-Gurion University of the Negev, Be'er Sheva, Israel, p 341-348

Ahmed KS (2003) Comfort in urban spaces: defining the boundaries of outdoor thermal comfort for the tropical urban environments. Energy Build 35:103-110

Akbari H (1995) Cool construction materials offer energy savings and help reduce smog. ASTM (Am Soc Test Mater) Standard News, Nov. 1995, p 32-37

Ali-Toudert F, Mayer H (2006) Numerical study on the effects of aspect ratio and orientation of an urban street canyon on outdoor thermal comfort in hot and dry climate. Build Environ 41:94-108

Ali-Toudert F, Djenane M, Bensalem R, Mayer H (2005) Outdoor thermal comfort in the old desert city of Beni-Isguen, Algeria. Clim Res 28:243-256

Arnfield AJ (1990) Canyon geometry, the urban fabric and nocturnal cooling: a simulation approach. Phys Geogr 11:220-239

Arnfield AJ (2003) Two decades of urban climate research: a review of turbulence, exchanges of energy and water, and the urban heat island. Int J Clim 23:1-26

ASHRAE (American Society of Heating, Refrigerating and Air-Conditioning Engineers) (1995). Addendum to Standard 55: thermal environmental conditions for human occupancy. ASHRAE, Atlanta, GA

Baker LA, Brazel AJ, Selover N, Martin C, McIntyre N, Steiner FR, Nelson A, Musacchio L (2002) Urbanization and warming of Phoenix (Arizona, USA): impacts, feedbacks and mitigation. Urban Ecosyst 6:183-203

Bruse M (1999) The influences of local environmental design on microclimate. $\mathrm{PhD}$ thesis, University of Bochum (in German)

Bruse M (2004) ENVI-met 3.0: updated model overview. University of Bochum. Available at: www.envi-met.com

Burian SJ, Velugubantla SP, Brown MJ (2002) Morphological analyses using 3D building database: Phoenix, Arizona, LA-UR-02-6726. Los Alamos National Laboratory, Los Alamos, NM

Correa C (1989) The new landscape: urbanization in the third world. Butterworth Architecture, London

Deosthali V (1999) Assessment of impact of urbanization on climate: an application of bio-climatic index. Atmos Environ 33:4125-4133

de Schiller S, Evans JM (1998) Sustainable urban development: design guidelines for warm humid cities. Urban Design Int 3(4):165-184
Emmanuel R (2005) Thermal comfort implications of urbanization in a warm-humid city: the Colombo Metropolitan Region (CMR), Sri Lanka. Build Environ 40:1591-1601

Emmanuel R, Johansson E (2006) Influence of urban morphology and sea breeze on hot humid microclimate: the case of Colombo, Sri Lanka. Clim Res 30:189-200

Fanger PO (1970) Thermal comfort: analysis \& applications in environmental engineering. McGraw-Hill, New York

Gan G (2001) Analysis of mean radiant temperature and thermal comfort. Build Serv Eng Res 22(2):95-101

Greene JS, Kalkstein LS (1996) Quantitative analysis of summer air masses in the eastern United States and an application to human mortality. Clim Res 7:43-53

Guhathakurta S, Gaver S, Gober P, Grossman-Clarke S, Zehnder J (2005) The impact of urban heat islands on water use: the case of Phoenix metropolitan area. N Am Meet Reg Sci Assoc Int, Nov 10-12, Las Vegas, NV

Hart M, Bontempo B, George L, Sailor D, Semenza J (2006) A multi-faceted approach to assessing human responses to extreme heat, poor air quality and public advisories. In: Lindqvist S, Grimmond CSB, Eliasson I (eds) Proc 6th Int Conf Urban Clim (ICUC-6). University of Göteborg, p 108-111

Höppe P (1999) The physiological equivalent temperature: a universal index for the biometeorological assessment of the thermal environment. Int J Biometeorol 43:71-75

Höppe P (2002) Different aspects of assessing indoor and outdoor thermal comfort. Energy Build 34:661-665

ISO (International Organization for Standards) 7730 (1994) Moderate thermal environments: determination of the PMV and PPD indices and specification of the conditions for thermal comfort, 2nd edn. 1994-12-15, Ref no. ISO 7730:1994(E)

Jendritzky G, Nübler W (1981) A model analyzing the urban thermal environment in physiologically significant terms. Arch Meteorol Geophys Bioclim Ser B 29:313-326

Johansson E (2006) Influence of urban geometry on outdoor thermal comfort in a hot dry climate: a study in Fez, Morocco. Build Environ 41:1326-1338

Johansson EJ, Emmanuel R, (2006) The influence of urban design on the outdoor thermal comfort in the hot, humid city of Colombo, Sri Lanka. Int J Biometeorol 51(2): 119-133

Kalkstein LS, Davis RE (1989) Weather and human mortality: An evaluation of demographic and interregional responses in the United States. Ann Assoc Am Geogr 79:44-64

Kalkstein LS, Valimont KM (1986) An evaluation of summer discomfort in the United States using a relative climatological index. Bull Am Meteorol Soc 67(7):842-848

Keim SM, Guisto JA, Sullivan JB Jr (2002) Environmental thermal stress. Ann Agric Environ Med 9:1-15

Kennedy D (2007) Sustainability. Science 315(5812):573

Koch W (1962) Relationship between air temperature and mean radiant temperature in thermal comfort. Nature 196:587

Kyle WJ (1992) Summer and winter patterns of human thermal stress in Hong Kong. In: Kyle WJ, Chang CP (eds) Proc 2nd Int Conf E Asia W Pac Meteorol Clim. World Scientific, Hong Kong, p 575-583

Lee SM, Fernando HJS (2004) Evaluation of mesoscale meteorological models, MM5 and HOTMAC, using PAFEX-1 data. J Appl Meteorol 43:1133-1148

Matzarakis A, Mayer H, Iziomon MG (1999) Applications of a universal thermal index: physiological equivalent temperature. Int J Biometeorol 43:76-84

Mayer H, Höppe P (1987) Thermal comfort of man in different urban environments. Theor Appl Climatol 38:43-49 
Nikolopoulou M, Steemers K (2003) Thermal comfort and psychological adaptation as a guide for designing urban spaces. Energy Build 35(1):95-101

NIOSH (National Institute of Occupational Safety and Health) (1986) Criteria for a recommended standard: occupational exposure to hot environments, revised criteria. Publ No. 86-113

Oke TR (1982) The energetic basis of urban heat island. Q J R Meteorol Soc 108(455):1-24

Oke TR (1987) Boundary layer climates. Methuen, London

Oke TR (1988) The urban energy balance. Prog Phys Geogr 12:471-508

Oke TR (1991) Climate of cities. In: Baer F, Canfield NL, Mitchell JM (eds) Climate from a human perspective: a tribute to Helmut E. Landsberg. Kluwer, Dordrecht, p 61-75

Rosenfeld AHR, Akbari H, Romm JJ, Pomerantz H (1998) 'Cool communities': strategies of urban heat island mitigation and smog reduction. Energ Tech 28:51-62

Rosenlund H, Johansson E, Emmanuel R (2006) UHI and buildings: effect of urban heating on the energy use in commercial buildings in a warm humid city. In: Lindqvist

Editorial responsibility: Helmut Mayer, Freiburg, Germany
S, Grimmond CSB, Eliasson I (eds) Proc 6th Int Conf Urban Clim. (ICUC-6) University of Göteborg, p 528-531

Saitoh TS, Hoshi H (1993) Urban warming in Tokyo metro area and counter-plan to improve future environment. IEEE Transactions 9338-6:2.887-2.892

Spagnolo J, de Dear R (2003) A field study of thermal comfort in outdoor and semi-outdoor environments in subtropical Sydney, Australia. Build Env 38(5):721-738

Todhunter PE (1990) Microclimatic variations attributable to urban-canyon asymmetry and orientation. Phys Geog 11(2):131-141

Tomita T, Kusaka H, Akiyoshi R, Imasato Y (2006) Thermal and geometric controls on the rate of near-surface air temperature changes in a medium-size, mid-latitude city. In: Lindqvist S, Grimmond CSB, Eliasson I (eds) Proc 6th Int Conf Urban Clim. (ICUC-6) University of Göteborg, p 338-341

Unger J, Balazs B, Sumeghy Z, Gal T (2006) Multiple variable model for estimating the maximum UHI using 2 and 3 dimensional surface parameters. In: Lindqvist S, Grimmond CSB, Eliasson I (eds) Proc 6th Int Conf Urban Clim. (ICUC-6) University of Göteborg, p 346-349

Submitted: July 13, 2006; Accepted: June 4, 2007 Proofs received from author(s): August 24, 2007 